\title{
Methodological and institutional considerations for the use of 360-degree video and pet animals in human subject research: An experimental case study from the United States
}

\author{
Martin Swobodzinski ${ }^{1}$ (D) . Mika Maruyama ${ }^{2}$. Eric Mankowski ${ }^{1}$
}

Published online: 11 September 2020

(C) The Psychonomic Society, Inc. 2020

\begin{abstract}
Head-mounted virtual-reality headsets and virtual-reality content have experienced large technological advances and rapid proliferation over the last years. These immersive technologies bear great potential for the facilitation of the study of human decision-making and behavior in safe, perceptually realistic virtual environments. Best practices and guidelines for the effective and efficient use of 360-degree video in experimental research is also evolving. In this paper, we summarize our research group's experiences with a sizable experimental case study on virtual-reality technology, 360-degree video, pet animals, and human participants. Specifically, we discuss the institutional, methodological, and technological challenges encountered during the implementation of our 18-month-long research project on human emotional response to shortduration 360-degree videos of human-pet interactions. Our objective in this paper is to contribute to the growing body of research on 360-degree video and to lower barriers related to the conceptualization and practice of research at the intersection of virtual-reality experiences, 360-degree video, live animals, and human behavior. Practical suggestions for human-subject researchers interested in utilizing virtual-reality technology, 360-degree videos, and pet animals as a part of their research are discussed.
\end{abstract}

Keywords Virtual reality $\cdot 360$-degree video $\cdot$ Human emotion $\cdot$ Pet dogs $\cdot$ Experimental design

\section{Introduction}

Immersive technologies such as augmented reality (AR) and virtual reality (VR) provide new modalities, applications, and interfaces for human-computer interaction (Stanney, 1995; Zheng et al., 1998; Halarnkar et al., 2012; Jung \& tom Dieck, 2017; Rubio-Tamayo et al., 2017). These technologies have been employed in recreational and professional settings (Nee \& Ong, 2013; Bonetti et al., 2018; Damiani et al., 2018; Neumann et al., 2018; Yung \& Khoo-lattimore, 2019) and informed research and teaching practice across a diverse range of disciplinary fields (Hwa Choi, 2016; Howard, 2017; Kavanagh et al., 2017; Pan \& Hamilton, 2018), in particular as it comes to behavioral research on human experiences in space and place (e.g.,

Martin Swobodzinski

swobod@pdx.edu

1 Portland State University, Portland, OR, USA

2 Clark College, Vancouver, WA, USA
Schuemie et al., 2001; Riva et al., 2007; Malloy \& Milling, 2010; Meyerbröker \& Emmelkamp, 2010; Schultze, 2010; Bohil et al., 2011; Annerstedt et al., 2013; Diemer et al., 2014; Turner \& Casey ,2014; Felnhofer et al., 2015; Serrano et al., 2016; Boletsis, 2017). Current-generation VR devices, in particular, combine affordability with highresolution displays, low latency, sensor arrays, and graphic processing capabilities that afford increasingly immersive experiences that have only became attainable over the last few years (Anthes et al., 2016).

The dissemination of AR/VR technology in society is catalyzed by large investments of prominent commercial businesses entities and the availability of affordable AR/VR end-consumer software products and platforms that allow for the publishing and viewing of AR/VR content. In particular, 360-degree video poses comparatively low barriers to the creation of content that lends itself to recreational applications, considering the wide selection and general affordability of recreational 360-degree cameras (Tan et al., 2018; Ferdig \& Kosko, 2020). In the context of research, 360-degree video has also received considerable attention, as evidenced by the growing number of research 
publications pertaining to technological aspects of 360degree such as adaptive video streaming (Qian et al., 2016, 2018; Corbillon et al. 2017; Nasrabadi et al. 2017). Apparent within the body of recent research pertaining to 360-degree video is a relative scarcity of human-centric studies that employ 360-degree video content as a stimulus material (Bessa et al., 2016; Kavanagh et al., 2016; Rupp et al., 2016; Stupar-Rutenfrans et al., 2017; Aitamurto et al., 2018; Lee et al., 2018; Schöne et al., 2020; Hu et al., 2020), in particular with sizable sample sizes (Tse et al., 2017; Rupp et al., 2019; Mazumder et al., 2020), as opposed to those studies that research 360-degree video as the prime subject of interest (Hosseini \& Swaminathan, 2016; Kopf, 2016; Afzal et al., 2017; Su \& Grauman, 2017; Domański et al., 2017). Most importantly, best practices for the use of 360-degree video in research have yet to emerge, and will likely require domain-specific solutions and contextspecific applications rather than a single one-size-fits-all solution (Roche \& Gal-Petitfaux, 2017; Van Damme et al., 2019; Mabrook \& Singer, 2019; Benzina et al., 2020; Zolfaghari et al., 2020), as even metrics for the assessment of the quality of 360-degree video continue to be negotiated (Tran et al., 2017; Xie et al., 2017; Van den Broeck et al., 2017; Tran et al., 2018; Frans Fela et al., 2020; Xu et al., 2020).

In this paper, we report on the institutional and methodological challenges that we encountered during the implementation of an 18-month-long collaborative experimental research project on human emotion, 360degree video, and live pet animals at two American institutions for higher learning. Within this context, we provide suggestions to facilitate research by investigators engaging in experimental work at the nexus of VR/AR technology, live animals, and human participants, with particular consideration for the utilization of high-definition 360-degree VR video showcasing pet dogs. We expect this paper to be foremost useful to researchers who are interested in the strategic and effective use of 360-degree video and pet animals in behavioral human-subject research. Our assumption throughout this paper is that the reader has prior knowledge on and experience with institutional and practical requirements pertaining to human-subject testing but less so in regard to conducting experimental research with VR technology and live animals, as was the case for our research group at the onset of our study.

In the following section, we provide a brief overview of our experimental study, including a description of its motivation and implementation. Next, we discuss the institutional considerations related to research-integrity oversight requirements at institutions of higher education in the United States for research with live animals, in general, and pet dogs, in particular. Following that, we report on the methodological challenges related to the use of VR technology and 360-degree video stimulus materials. Also included in that section is a discussion on the current state of VR devices and projections pertaining to the technological frontier of VR content in terms of visual fidelity. In the last section, we conclude the paper with a summary of our recommendations and a brief outlook.

\section{Brief description of experimental study}

In this section, we provide a brief description of the motivation, theoretical underpinnings, and general setup of our study. The description is intended to provide a sufficient frame of reference for our discussion of the institutional and methodological challenges in the subsequent sections. For a detailed description of our experimental design, procedure, data, and analysis, we defer to a future effort.

Our study investigated the effects of short-duration exposure to depictions of human-animal interactions in 360-degree video on psychological and physiological indicators in non-clinical research subjects. The study was motivated by two areas of research. First, positively valenced interactions with pet animals have been shown to induce desirable psychological and physiological responses in humans, with positive effects reported for both live (Baun et al., 1984; Serpell, 1991; Wilson, 1991; Friedmann \& Thomas, 1995; Miller et al., 2009; Abate et al., 2011; Kruger \& Serpell, 2010; Berget \& Grepperud, 2011; Levine et al., 2013; Vrbanac et al., 2013; Kamioka et al., 2014; Stefanini et al., 2015; Maber-Aleksandrowicz et al., 2016; Giuliani \& Jacquemettaz, 2017; Charry-Sánchez et al., 2018; Hu et al., 2018) as well as robotic pets (Moyle et al., 2013; Banks et al., 2008). Second, past studies found that higher-immersion VR equipment produced greater positive effects in humans compared to less immersive technology such as a computer screen. However, it is currently unknown to which extent positive effects of human-animal interactions translate to VR, and specifically to depictions of positive human-animal interactions in 360-degree video. Our group hypothesized that a currentgeneration VR device showcasing 360-degree videos of human-animal interactions induces greater change in core affect activation and valence (Ekkekakis \& Russell, 2013), heart rate, and blood pressure in VR-group participants than in participants who were exposed to companion animals through less immersive means (i.e., desktop video, photo books).

A 360-degree video of human-dog interactions was therefore an essential component of our research study in that the video had to be in place before any experimentation with human subjects could commence. The video showcased a single adult observer seated in a mid-sized room among a small number of dogs, with the dogs interacting 
with the observer and each other in a playful, good-natured manner. Considering the importance of touch and eye contact as it comes to positive physiological responses in the human-dog dyad and human-dog bonding (Hosey \& Melfi, 2014; Kaminski et al., 2019; Marshall-Pescini et al., 2017; Nagasawa et al., 2015; Téglás et al., 2012; Waller et al., 2013; Meyer \& Forkman, 2014; Kuhne et al., 2012b; Feuerbacher \& Wynne, 2015; Kuhne et al., 2012a; Kekecs et al., 2016; McCune et al., 2014), we deliberatively put an emphasis on capturing close-proximity human-animal interactions such as petting, eye contact, and playing. Figure 1 presents a typical scene from the video that we recorded.

All stimulus materials were derived from the single 10-min-long 360-degree high-definition video that our group created in-house. The video was recorded using a professional, high-resolution 360-degree camera ${ }^{1}$ that was attached to the top of a helmet worn by the single observer, approximating a first-person perspective on the surrounding space. Furthermore, we employed the Oculus $\mathrm{Rift}^{2}$, a commercial off-the-shelf VR headset for our VR group participants.

We collected human-subject data from December 2018 through May 2019 at two dedicated lab spaces on the campuses of the research group members. During the data collection period, the two lab spaces were available to participants during regular business hours for $20 \mathrm{~h}$ per week. However, the weekly average number of participants completing the experiment at both study sites was 5 (Fig. 2), irrespective of persistent recruitment efforts throughout the data collection period comprised of the campus-wide distribution of flyers, in-class announcements, and social media postings. Participants were able to self-manage their appointments through an online scheduling service ${ }^{3}$. Overall, 285 participants took part in the experiment.

\section{Institutional considerations for experimental studies using animals and VR technology}

In this section, we discuss the unanticipated challenges the were afforded to our group by the combination of pet dogs, 360-degree video, and overall VR-centric experimental human-subject study design. Our research study underwent a substantial preparation and approval process regarding research integrity oversight, given that our study involved both animal and human participants. Whereas our team was familiar with the institutional expectation and requirements

\footnotetext{
${ }^{1}$ https://www.insta360.com/product/insta360-pro/

${ }^{2}$ https://www.oculus.com/rift/

${ }^{3}$ https://10to8.com
}

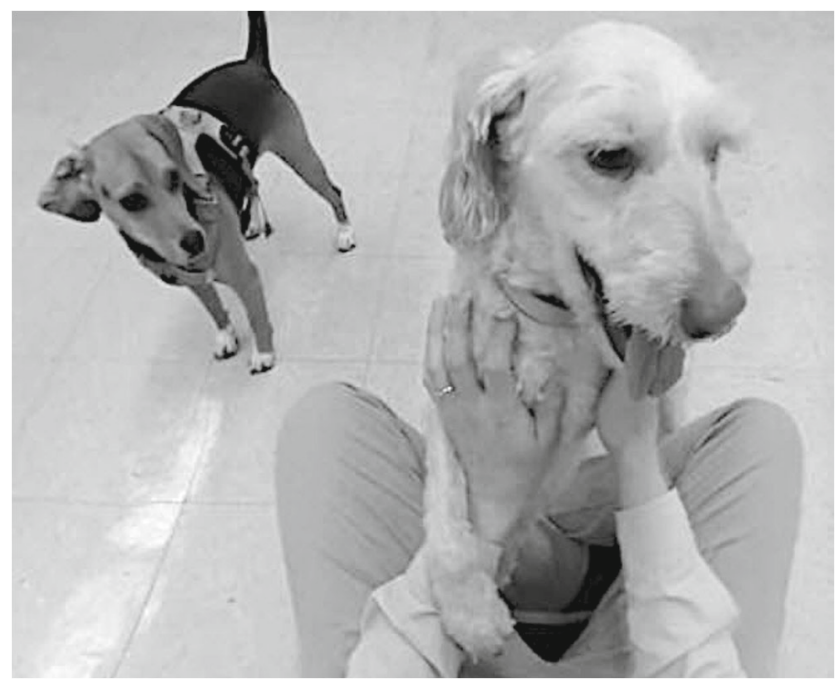

Fig. 1 Screenshot from the 360-degree video that we created for our experimental study for use as stimulus materials. The video captured the interactions of a single human individual with two non-reactive dogs and their playful interaction with each other and the human observer

regarding the protection of the welfare of human research subjects, commonly administered in the United States through a university's Institutional Review Board (IRB), the institutional research oversight requirements regarding the involvement of animals were unclear to us. Below, we provide a summary of our experiences pertaining to research integrity oversight during our study.

\section{Institutional considerations for research activities with live animals}

As our group prepared for the creation of the stimulus materials for our study, it became apparent that the institutional oversight requirements for the involvement of live animals were generally more stringent than those for human participants. Even though our focus here is on the animal-research oversight regulations for institutions of higher education in the US, we expect similar regulations and procedures in countries that have implemented safeguards for the ethical use and the wellbeing of animals in research (Baumans, 2004; Caporale et al., 2005; Institute of Medicine (US) and National Research Council (US), 2012; Sinmez \& Yasar, 2019). ${ }^{4}$

Whereas single-member reviews (i.e., Designated Member Review; DMR) of research protocols are often sufficient for no- to minimal-risk studies with human participants, research activities with live animals usually require a

\footnotetext{
$\overline{{ }^{4} \text { https://www.infrafrontier.eu/procedures/animal-welfare-and-ethics/ }}$ eu-and-national-regulations-animal-experimentation
} 


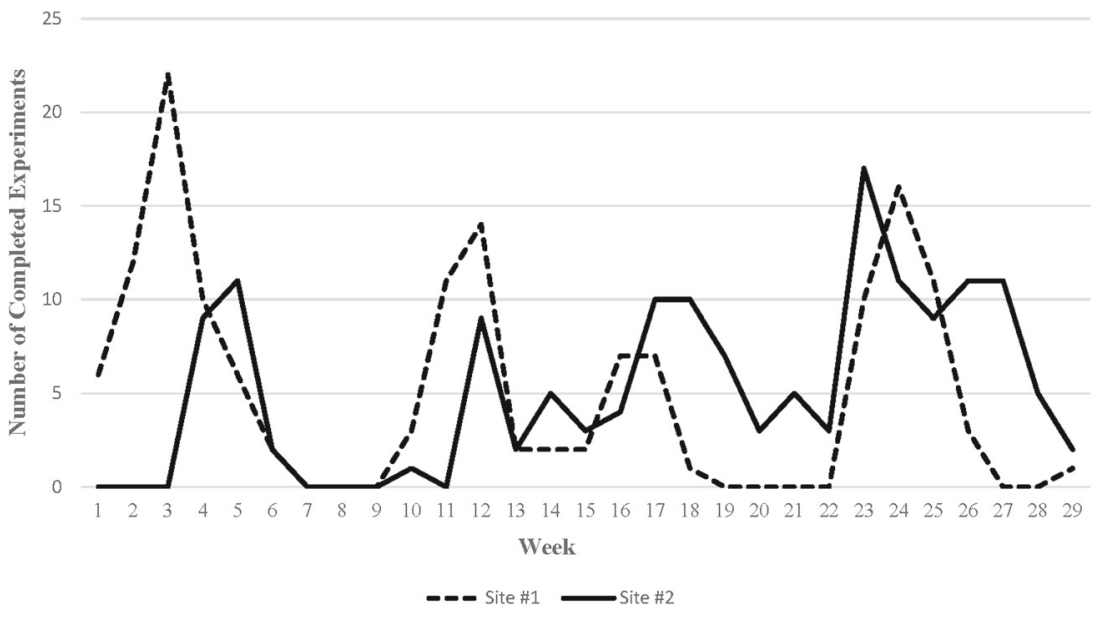

Fig. 2 Number of completed experiments across our two study sites by week. Our data collection took place over a 29-week period from December 2018 through June 2019. Participation numbers across the two study sites were similar, with consistent decreases in participation during weeks when courses were not in session (both locations operate under the 10-week quarter system), and an average of five participants per week

review by the Institutional Animal Care and Use Committee (IACUC; Everitt \& Berridge, 2017). Exemptions to fullcommittee review are limited to research activities where no direct contact with or manipulation of the behavior of an animal occurs (Monamy, 2017). For instance, documenting the behavior of animals at a distance and location that does not allow the observed animals to sense the presence of the researcher qualifies for DMR (Silverman et al., 2014). Considering that a core requirement for our experimental study was the creation of 360-degree video of playful interactions between a researcher and pet dogs, DMR was not an option, and our project was subject to a full IACUC review. Table 1 lists the periods of major activities related to research integrity oversight pertaining to our project.

Overall, the period of most effort pertaining to the IACUC review and approval process for our research protocol span a period of approximately three and a half months. We estimate that the time allocation for the two research group members who led the animal-related research activities to be the equivalent of 200 work hours. This number only pertains to our research group, with effort and time contributed by members of the university administration and campus community non-accounted for here since such information is not available to us.

Apart from the time necessary for the review of our application materials and study design by the IACUC committee, a considerable amount of time was required to establish the details of our research protocol as far as the use of live pet dogs in our project was concerned. Initially, we anticipated that the video recording would take place on the premises of a local animal-welfare organization (e.g., Humane Society or Animal Services), considering that these organizations would be able to supply appropriate facilities and staff support that could be leveraged for our project. As we learned after our initial consultations with members of the university's animal research integrity office, this approach was unlikely to be attainable in a timely manner due to the requirement to have in place written agreements on animal-research oversight procedures and regulations with outside organizations (Everitt \& Berridge, 2017).

First and foremost, academic institutions who receive funds under the U.S. Public Health Service (PHS) and conduct animal activities require to have on file a formal assurance with the Office of Laboratory Animal Welfare $(\mathrm{OLAW})^{5}$. The chief responsibility of OLAW is to monitor compliance with the Policy on Humane Care and Use of Laboratory Animals by assured institutions to ensure the humane care and use of animals in PHS-supported research, testing, and training (Silverman et al., 2014). Apart from the National Institutes of Health (NIH), PHS funding extends to the National Science Foundation (NSF), the Centers for Disease Control and Prevention (CDC), and the Food and Drug Administration (FDA). OLAW does not oversee animal activities funded by the Department of Defense (DoD), the U.S. Department of Agriculture (USDA), and neither does its oversight extend to nonprofit or for-profit organizations (Everitt \& Berridge, 2017). Hence, it is unlikely for any given local animal shelter or rescue to have OLAW Assurance. If researchers at an institution with OLAW Assurance choose to conduct animal activities at a secondary institution without OLAW Assurance, the activities need to be subcontracted to

\footnotetext{
${ }^{5}$ https://olaw.nih.gov/home.htm
} 
Table 1 Overview of research-integrity activities related to institutional research oversight requirement by the Institutional Review Board (IRB) and the Institutional Animal Care and Use Committee (IACUC)

\begin{tabular}{|c|c|}
\hline Period & Project activity / Event \\
\hline July 2017 & Recommendation for funding \\
\hline Aug. 2017 & Submission of IRB application for expedited review \\
\hline : & Approval of IRB application \\
\hline Sep. 2017 & Initial IACUC review \\
\hline : & Request for full IACUC application \\
\hline : & Consultation: Sponsored projects, research integrity, general counsel \\
\hline Oct. 2017 & Animal care and use training, CITI program \\
\hline Nov. 2017 & Consultations: Dog behavior specialists, animal welfare organizations \\
\hline : & Submission of full IACUC application \\
\hline : & Request for minor revisions to IACUC application \\
\hline : & Submission of full IACUC application with minor revisions \\
\hline : & IACUC application forwarded to IACUC committee \\
\hline Dec. 2017 & Approval of IACUC application \\
\hline : & Submission of approved documents to funding agency \\
\hline Feb. 2018 & Final approval from funding agency \\
\hline : & Notice of award \\
\hline : & Fully executed subaward to partner institution \\
\hline Mar. 2018 & Consultations with dog behavior specialists, organizations \\
\hline Apr. 2018 & Screening, recruitment, and scheduling of dogs and owners \\
\hline June 2018 & Recording of 360-degree video content \\
\hline July 2018 & Post-processing of 360-degree video files \\
\hline$:$ & Creation of additional stimulus materials \\
\hline Oct. 2018 & Creation of data collection documents \\
\hline : & Creation of scripts for research assistants \\
\hline : & Training workshops for research assistants \\
\hline Nov. 2018 & Piloting of research scripts \\
\hline : & Final revision of data collection documents and scripts \\
\hline Dec. 2018 & Start of data collection with human participants \\
\hline June 2019 & End of data collection with human participants \\
\hline
\end{tabular}

Whereas the IRB is tasked with the protection of the rights and welfare of human research subjects, the IACUC oversees the ethical use of animals in research at an academic research institution. IACUC-related activities amounted to three and a half months of concentrated effort by two members of our research group, a significant period of time within the 18-month time span of our research study

the secondary institution and the secondary institution be named a performance site by the prime awardee institution (Silverman et al., 2014; Everitt \& Berridge, 2017; Monamy, 2017). After the review and approval of the performance site, the primary institution will work with OLAW to negotiate an assurance with the secondary institution. Such an approach is likely to require significant buy-in by the partnering organization and the explicit allocation of dedicated staff time, which might render it non-feasible within the time constraints of a shorter-duration research study such as ours. In this context, research procedures with pet animals on a university campus have to consider that university policies often prohibit the presence of pet animals other than emotional support and service animals on a university campus, in particular as it comes to indoor spaces. ${ }^{67}$

Another consideration in this context is that shelter environments are often stressful for the animals and their behavior inside of the shelter environment may not be indicative of the behavior that the animals will exhibit in a different space (Palma et al., 2005). Dogs are highly sensitive to changes in their environment, which can act as a stressor on the dogs and in turn lead to nondesirable, reactive behavior such as barking and biting (Wright \& Nesselrote, 1987; Lindsay, 2000). After adoption

\footnotetext{
${ }^{6}$ https://policy.uconn.edu/2017/06/12/animals-on-campus/

${ }^{7}$ https://policies.utexas.edu/policies/animals-campus ${ }^{8}$
} 
from a shelter, it is common to take multiple weeks for the dog's typical personality to emerge, including nondesirable reactive behavior due to unforeseeable factors such as genetics, past experiences, sensory triggers, and fear responses (Lord et al., 2008). Shelter animals may also become unavailable at any time due to adoption. Thus, it may be unpredictable and difficult to identify dogs coming from a shelter environment who would behave as we intended to showcase in our video, that is, relaxed and playful. In turn, our group decided to move the capturing of the 360-degree video to a suitable room on our university campus and constrain our selection of dogs to those currently living with their private owners.

\section{Research protocol for the use of pet dogs}

For the capturing of the 360-degree video, careful thought had to be given to establishing a research protocol that would safeguard the well-being of the dogs, their owners, as well as the other individuals on campus who might cross paths with the dogs during their presence on the university grounds. To minimize the possibility of reactive behavior, before individual dogs and their owners were invited to take part in the video recording events, we devised an online screening survey to make sure that it was appropriate for the dogs to participate in the video recording. The questions that were asked followed common standards in veterinary behavior and dog daycare facilities (Hsu \& Serpell, 2003; Duffy et al., 2014; Wiener \& Haskell, 2016). ${ }^{9}$ In addition to questions on the age, size, and breed of the dog, a particular focus was on the presence or absence of prior occurrences of reactive behavior towards other dogs or human strangers. The survey also inquired into the status of vaccinations and medical examinations. If the dog's owner stated that their dog exhibited any reactive behavior in the past, the dog was excluded from further consideration. Furthermore, we excluded dogs in poor health and those without recent veterinary care or up-to-date vaccination records.

Subsequently, we invited a group of eight eligible dogs and their owners to partake in the video recording procedure. The video recording procedure was comprised of two separate 1-hour long events on two consecutive days. Both events were aimed at assessing the social compatibility of the invited dogs while introducing the dogs to each other, the researchers, the video equipment, and the study room through a structured, step-wise process. All interactions among the dogs and researchers were closely monitored by two dog-behavior specialists. Furthermore, all researchers

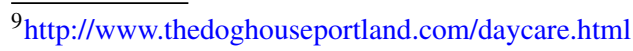

who interacted with the dogs completed IACUC researchintegrity and animal-research training requirements. For the final selection of eligible dogs for the video recording, we deferred to the observations and professional judgement of the dog behavior professionals to identify those dogs that exhibited greatest compatibility. Participation in the video recording sessions was incentivized by a modest stipend of $\$ 40$ for each dog owner and event. Dogs owners assumed responsibility for transporting their dogs to the study room in a safe manner.

During both sessions, dog owners and on-leash dogs met in front of the study room, with the two dog behavior professionals providing advice on assessing and minimizing any distress among the dogs. The dogs were sequentially introduced to each other and the researchers, and, subsequently, the study room and recording equipment, first on-leash and then off-leash. During all times, the dog behavior professionals monitored for signs of stress, reactivity, aggression, and/or discomfort and provided advice on the duration of each step. Out of the group of eight eligible dogs that were invited, two dogs were ultimately selected for the video recording.

On the second day, once the dog behavior professionals confirmed that the selected dogs had gotten used to the room and exhibited calm, positive attitudes toward the environment and each other while being off-leash, the recording of the video commenced. During the capturing of the video, the camera was set to record continuously. A single researcher, a single dog behavior specialist, and the two selected dogs were collocated in the study room. The dogs remained off leash and were free to roam the room. The researcher was seated in a chair in the middle of the study room, wearing a helmet with a mounted 360-degree, virtual-reality camera. The researcher remained seated, facing in the same direction, and avoided loud speaking as well as movements of the body and head. A small treat was placed in the researcher's shirt pocket to entice interest by the dogs. The dog behavior specialist remained standing silently in a corner of the room and periodically bounced a toy. All interactions between the researcher and the dogs were driven by the dogs' natural behaviors and personalities. We observed the following interactions: (a) the dogs behaved in a friendly manner; (b) the researcher threw a toy and one of the dogs fetched it; (c) the researcher reached for and petted one of the dogs; and (d) the researcher placed one of the dogs on his lap and petted it. Once the video recording session concluded, the dogs and dog owners were debriefed by the researchers and guided one-by-one on separate routes towards the exits to minimize the potential for further arousal among the dogs. No adverse events occurred leading up to or during any of the sessions. 


\section{Research considerations for the use of VR technology}

In this section, we discuss the requirements for use of VR technology in research. Specifically, we first summarize the space and computing requirements pertaining to current-generation VR headsets. Subsequently, we discuss technological and technical considerations for the creation of 360-degree video for VR.

\section{Lab space and computing requirements}

Our two labs were arranged so that each space could afford 360-degree tracking of the VR headset and controllers through external tracking sensors (i.e., outside-in tracking) (i.e., outside-in tracking Anthes et al., 2016). ${ }^{10}$ Our lab spaces offer approximately 80 square feet of obstructionfree space dedicated to the VR setup, with the minimal space requirements for room-scale VR setups usually no less than 30 square feet. Three tracking sensors in a triangular arrangement (two up front, one in the back) are required for seamless 360-degree tracking of the headset. ${ }^{11}$ The sensors can be placed on table surfaces or, for generally better coverage, mounted on walls at a recommended height of 8 feet using third-party wall mounts. Each sensor affords a conical field of coverage, with the ideal placement of each sensor such that its cone is maximized and unobstructed, with zones of partial overlap between the individual tracking cones, as illustrated in Fig. 3.

Some recent VR headsets have abandoned external tracking sensors in favor of inside-out tracking capabilities (Anthes et al., 2016). In inside-out positional tracking, cameras and/or sensors are integrated into the VR device itself instead of relying on external hardware. Considering that they have fewer requirements for a functional VR setup, VR devices with inside-out tracking generally require fewer steps to utilize and maintain ${ }^{12}$. In addition, forgoing external tracking hardware is a necessity for self-contained, potentially wireless VR headsets, which are generally seen as more user friendly ${ }^{13}$. Having said that, inside-out tracking has the drawback that objects and equipment that are not in the field of view of the tracking hardware, often times realized through the integration of video cameras in the front of the headset, will not be accounted for. ${ }^{14}$ Irrespective of the tracking system, current VR headsets share similar minimum and maximum room

\footnotetext{
${ }^{10}$ https://xinreality.com/wiki/Outside-in_tracking

${ }^{11}$ https://www.pcmag.com/how-to/how-to-set-up-the-oculus-rift

${ }^{12}$ https://www.mechatech.co.uk/journal/ why-will-inside-out-tracking-be-the-future-of-vr

${ }^{13} \mathrm{https} / / / \mathrm{www}$.wareable.com/vr/inside-out-vs-outside-in-vr-tracking-343

${ }^{14}$ https://www.outerrealmvr.com/single-post/2019/10/24/

Finally-Achieving-Easy-to-Use-Truly-Immersive-Virtual-Reality
}

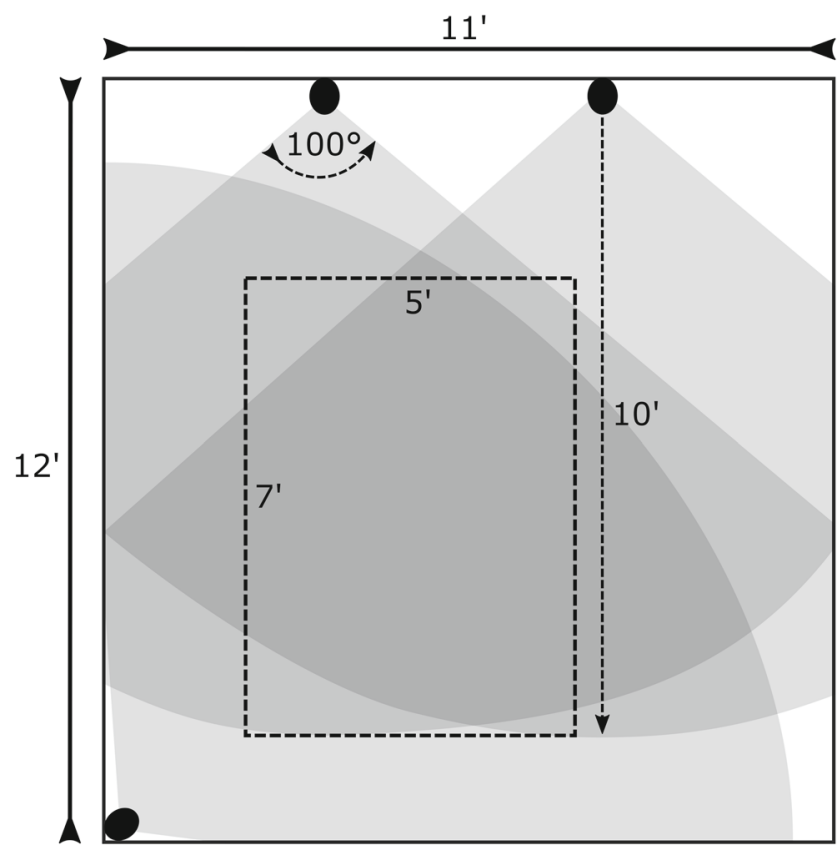

Fig.3 A typical arrangement of an external room-scale, outside-in VR tracking setup in a mid-sized room using three sensors (shown as black solid ellipses). For the consumer version of Oculus Rift, the horizontal coverage of each sensors is about 100 degrees horizontally and 75 degrees vertically. In the figure, the overlap among the cone-shaped horizontal coverage areas of multiple sensors is visualized by darker shades of grey. For optimal tracking of head movements, the area in which most of the VR activity occurs should be covered by all three sensors. The rectangle with the dashed border represents the suggested minimal area for room-scale tracking. It is likely that the recommended room size for room-scale tracking will remain the same to VR devices using inside-out tracking

size requirements. Table 2 provides an overview of major consumer-level VR headsets and their specifications.

Until advances in technology miniaturization and wireless data transfer surpass the processing demands of highfidelity, high-resolution VR headsets, greatest visual fidelity will remain within the purview of VR headset that are tethered to a desktop computer with a powerful, dedicated graphics processing unit (GPU) ${ }^{15}$. In the context of computer equipment for VR devices, we recommend purchasing computer workstations that come pre-configured with a high-end, VR-ready GPU over separate purchases of a nonVR workstation and aftermarket GPU. We assume here that most academic institutions in the U.S. rely on computer equipment purchasing channels and vendor service contracts similar to ours (i.e., Dell). The high-end GPUs required for tethered VR headsets have significant power supply and physical space requirements in terms of both width and height compared to lower-tier graphics cards that are geared towards business tasks. In our case, the models of computer workstations that were available to us for

\footnotetext{
${ }^{15}$ https://www.aniwaa.com/guide/vr-ar/types-of-vr-headsets/
} 
Table 2 Past and current major commercial VR headsets and their key specifications

\begin{tabular}{lllllllll}
\hline Year & $\begin{array}{l}\text { Hres } \\
\text { (per } \\
\text { eye })\end{array}$ & $\begin{array}{l}\text { Vres } \\
\text { (per } \\
\text { Eye })\end{array}$ & $\begin{array}{l}\text { Pixels } \\
\text { per } \\
\text { eye })\end{array}$ & $\begin{array}{l}\text { Total } \\
\text { pixels }\end{array}$ & $\begin{array}{l}\text { Resolution } \\
\text { moniker }\end{array}$ & $\begin{array}{l}\text { Type of } \\
\text { connec- } \\
\text { tion }\end{array}$ & $\begin{array}{l}\text { Positional } \\
\text { tracking }\end{array}$ & $\begin{array}{l}\text { Device } \\
\text { name }\end{array}$ \\
\hline 2013 & 640 & 800 & 512,000 & $1,024,000$ & $<1 \mathrm{~K}$ & Tethered & Outside-In & Oculus Developer Kit 1 \\
2014 & 960 & 1080 & $1,036,800$ & $2,073,600$ & $1 \mathrm{~K}$ & Tethered & Outside-In & Oculus Developer Kit 2 \\
2016 & 1080 & 1200 & $1,296,000$ & $2,592,000$ & $1 \mathrm{~K}$ & Tethered & Outside-In & Oculus Rift \\
2016 & 1080 & 1200 & $1,296,000$ & $2,592,000$ & $1 \mathrm{~K}$ & Tethered & Outside-In & HTC Vive \\
2018 & 1440 & 1600 & $2,304,000$ & $4,608,000$ & $1.5 \mathrm{~K}$ & Tethered & Outside-In & HTC Vive Pro \\
2019 & 1280 & 1440 & $1,843,200$ & $3,686,400$ & $1.3 \mathrm{~K}$ & Tethered & Inside-Out & Oculus Rift S \\
2019 & 1440 & 1600 & $2,304,000$ & $4,608,000$ & $1.5 \mathrm{~K}$ & Stand-Alone & Inside-Out & Oculus Quest \\
2019 & 2160 & 2160 & $4,665,600$ & $9,331,200$ & $2.2 \mathrm{~K}$ & Tethered & Inside-Out & HP Reverb \\
2019 & 2560 & 1440 & $3,686,400$ & $7,372,800$ & $2.5 \mathrm{~K}$ & Tethered & Outside-In & Pimax 5K Plus \\
2019 & 3840 & 2160 & $8,294,400$ & $16,588,800$ & $4 \mathrm{~K}$ & Tethered & Outside-In & Pimax 8K \\
2019 & 1440 & 1600 & $2,304,000$ & $4,608,000$ & $1.5 \mathrm{~K}$ & Tethered & Outside-In & Valve Index \\
2019 & 1440 & 1700 & $2,448,000$ & $4,896,000$ & $1.5 \mathrm{~K}$ & Tethered & Inside-Out & HTC Vive Cosmos \\
2019 & 1440 & 1600 & $2,304,000$ & $4,608,000$ & $1.5 \mathrm{~K}$ & Stand-Alone & Inside-Out & HTC Vive Focus Plus \\
2019 & 1440 & 1600 & $2,304,000$ & $4,608,000$ & $1.5 \mathrm{~K}$ & Tethered & Outside-In & HTC Vive Pro Eye \\
\hline
\end{tabular}

As it stands, current VR headsets closely align with the performance bandwidths of contemporary graphical processing units and video data transfer standards. Put differently, advances related to VR headsets are closely tied to incremental increases in the performance of high-performance graphical processing units

purchase order did not entail those with a pre-configured, VR-ready GPU. That, in turn, necessitated the purchase of an aftermarket GPU, which had us content with technical troubleshooting to get the aftermarket GPU ready for use, with a list of select difficulties as follows: 1. the supplemental power supply connectors on the workstation were vendor-specific and required the identification and purchase of an additional adapter that was not included with either the workstation or aftermarket GPU; 2. fitting the aftermarket GPU in terms of width required the reconfiguration of internal cards, including the removal of a cooling element from a controller card; 3 . fitting the aftermarket GPU in terms of height did not allow for the side access panel of the computer case to be re-attached and shut (in order to minimize the possibility of accidental contact with the innards of the workstation, we relocated it to a corner desk so that the exposed side of the case rested against a wall). Considering that computer manufacturers typically do not provide information on available internal physical space and types of power supply connectors, it remains unknown if any of these difficulties could have been avoided through the purchase of a different workstation model. Hence, our recommendation is to avoid aftermarket GPUs in favor of VR-ready preconfigured systems.

As an alternative to using a computer system with an internal GPU, for those otherwise underpowered desktop and notebook computers that are equipped with a highthroughput peripheral port (e.g., USB-C with Thunderbolt $3)^{16}$, VR-ready graphic processing capabilities can be achieved through the use of an external GPU enclosure. These ports offer large-bandwidth, bi-directional video data transmission capabilities that are sufficient to drive a VRready GPU in an external GPU enclosure (eGPU), while only introducing a modest overall performance decrease of 15-20\% as compared to an internal GPU. ${ }^{17}$. What is gained through the use of an eGPU is that the VR setup becomes flexible since the eGPU can be moved and connected to other computer systems that support the proper connector on an as-needed basis. Having high-performance graphic processing hardware available as a shared, modular resource is beneficial for any data processing scenario that relies on raw GPU power (e.g., VR equipment; video editing and processing; 3D modeling). Furthermore, aftermarket eGPUs are likely to avoid difficulties related to connecting and supplying power to the chosen GPU and should make near-future GPU upgrades a matter of a simple swap.

\footnotetext{
$\overline{{ }^{16} \mathrm{https}: / / w w w . l a p t o p m a g . c o m / a r t i c l e s / t h u n d e r b o l t-3-g u i d e ~}$

${ }^{17} \mathrm{~A}$ performance decrease of $20 \%$ is less than the expected performance difference between any given GPU and its successor or higher-tier model. In other words, a higher-level GPU in an external enclosure should perform at least to the level of last year's internal GPU of the same make
} 


\section{0-degree video for VR}

Three major parameters for the creation of 360-degree video for VR are resolution, frame rate, and monoscopy or stereoscopy, in particular as it comes to perceptions of the quality of the experience (Lambooij et al., 2007; Keshavarz \& Hecht, 2012; Ling et al., 2012; Allen et al., 2016). As with static images, resolution describes the number of pixels that are contained in each individual image captured by the video sensor, which typically determines the amount of detail resolved in each image, with higher resolution equating to greater detail. Frame rate is exclusive to videos and specifies how many static images are captured in a given time period, usually per second. Modern video standards often employ 24 frames per second, which is the minimum speed for motion in a video to appear smooth and realistic. Lastly, monoscopy and stereoscopy describes how many simultaneous video images are used in the VR video for the left and right eye. Stereoscopic video refers to 360degree video that uses two simultaneous, separate video images that provide a slightly offset perspective for each eye, which leverages human natural capacity for stereopsis (i.e., binocular vision) and depth perception. In monoscopic video, on the other hand, the same video image is shown to both eyes, resulting in less visual depth-related information being related to the brain.

Considering the benefits of stereoscopic over monoscopic imagery (IJsselsteijn et al., 2001; Henn et al., 2002; Ilgner et al., 2006; Baños et al., 2008; Faria et al., 2016; Loup-Escande et al., 2017), we used the highest resolution that was supported by our VR video camera ${ }^{18}$, that is, stereoscopic video at a resolution of $6 \mathrm{~K}$ and 30 frames per second. The video camera employed a configuration of six lenses that were equally spaced around the center line of the spherical camera housing. During recording, each lens captured an individual video file which was subsequently stitched together with third-party VR video editing software as a part of the post-processing period of the six source video files. The output of the stitching procedure was a single spherical (i.e., 360-degree) output video. We found that both professional editing software programs capable of processing 360-degree video that we tested ${ }^{19}$ required multiple iterations for the output of the stitching algorithm to be acceptable. With one software program, in particular, a single stitching seam was marked by pronounced warping and waviness, with the seam distorting the body of one of the dogs for a large part of the video. Further trial-and-error testing of the software settings eliminated such distortion and produced clean, non-distracting seams. Subsequently, we applied algorithmic motion stabilization to the video

\footnotetext{
${ }^{18}$ Insta360 Pro

${ }^{19}$ Adobe Premier Pro and SGO Mistika VR
}

to eliminate involuntary small movements of the helmetmounted camera during recording. As an artefact of this process, we noticed slight intermittent wandering of the perspective in the VR video when the VR headset was not moved. Given that it was reasonable to assume that participants in the VR headset group would continuously move their heads (e.g., to track the dogs or explore the surrounding VR space) rather than remain motionless for any period of time, this artefact was not further concerning to us.

A point of concern, however, was that during the piloting of different monoscopic and stereoscopic videos that we generated from the source files, a number of our research assistants reported feeling motion sickness to the extent that they were not able to finish watching the 10-min-long videos in VR. Considering previous studies that studied stereoscopic imagery (Lambooij et al., 2007; Keshavarz \& Hecht, 2012; Schild et al., 2012; Allen et al., 2016) and those that utilized the same head-mounted display as us (Munafo et al., 2017; Chessa et al., 2019), certain discomfort in terms of motion sickness for the participants in the VR group was to be expected. However, one adjustment to reduce the occurrence of motion sickness among the study participants was to restrict the amount of VR exposure to $10 \mathrm{~min}$. After further pilot testing with members of our research group, we found that the stereoscopic video files were causing the reactions whereas the monoscopic videos did not. This might have been a product of the video player software and computer hardware, which we were not able to resolve. Furthermore, video files with a resolution greater than $4 \mathrm{~K}$ presented persistent problems during playback, with many files not being able to be played at all or only with prominent jitter of the video, which rendered these videos unwatchable. As a consequence, we opted for monoscopic video with a resolution of $4 \mathrm{~K}$ at 30 frames per second to function as our final stimulus video for the experiment with human participants. It is noteworthy that throughout the duration of our data collection, no participant prematurely stopped the experiment due to motion sickness. ${ }^{20}$

\section{Eye-resolution VR}

It is noteworthy that the displays that are used in current VR headsets have a long way to go in order to approach the visual fidelity of the human eye. For each new-generation model of a GPU, typically brought to market on an annual basis, iterative performance gains of $50 \%$ are typical over last-generation models of the same make. If one accepts that a comparison between electronic displays and the human

\footnotetext{
${ }^{20} \mathrm{~A}$ single adverse event occurred in which a participant fainted after a blood pressure measurement and was not able to complete the experiment. The event occurred before any exposure to the stimulus materials.
} 
Table 3 Considering that the field of view of current head-mounted displays (HMD) equates to about $25 \%$ of the available visual information in a spherical, 360-degree VR video (i.e., the part of the video sphere that the user is currently facing) at any given time, the amount of pixels being by the HMD can be approximated based on the total resolution of the spherical video

\begin{tabular}{lll}
\hline Hres (Video) & Resolution moniker & Hres (HMD) \\
\hline 2000 & $2 \mathrm{~K}$ & 500 \\
4000 & $4 \mathrm{~K}$ & 1000 \\
6000 & $6 \mathrm{~K}$ & 1500 \\
8000 & $8 \mathrm{~K}$ & 2000 \\
16,000 & $16 \mathrm{~K}$ & 4000 \\
32,000 & $32 \mathrm{~K}$ & 8000 \\
\hline
\end{tabular}

Current VR video cameras such as the Insta360 Pro are capable of producing 360-degree video with a resolution of up to $8 \mathrm{~K}$. In such a situation, the HMD would be able to display about 2000 horizontal pixels (i.e., $2 \mathrm{~K}$ ) across the field of view; that is, across both eyes of both eyes (or $1 \mathrm{~K}$ per eye). Practically, this is considerably less than current HMD displays are able to resolve natively-a circumstance that typically requires upscaling of the video to the native resolution of the HMD which often results in a loss of detail and an apparent blurriness when viewing VR videos using a HMD

eye is proper, an equivalent of perfect visual acuity for an adult viewer across the fovea (i.e., 20/20 vision) can reasonably be approximated to 2200 pixels per inch. At such pixel density, individual pixels would be imperceptible to the viewer wearing a VR headset, with a distance of 4 inches between the eyes and displays. Hence, the content shown on the displays would resemble life-like visual stimuli. ${ }^{21}$

Current-generation VR headsets employ display sizes of about 3 inches square per eye and provide a field of view that covers about one-fourth of the content of a spherical 360-degree space $^{22}$. This has direct implication for the amount of pixels that are displayed by a VR headset at any given time. Specifically, in order to achieve a pixel density of 2200 dpi (i.e., eye-resolution VR), one would require roughly 5 million pixels per inch square or 50 million total pixels per display, that is, a resolution of $8 \mathrm{~K}$ as far as the field of view of the headset is concerned. Conversely, and assuming that the entire spherical video is broadcasted to the VR headset, eye-resolution VR video would have to provide a resolution of $32 \mathrm{~K}$ (i.e., four times the $8 \mathrm{~K}$ resolution visible in the VR headset (Table 3). With VR video at $4 \mathrm{~K}$ resolution, as in our research project, the effective viewing resolution in the VR headset was about $1 \mathrm{~K}$, or 1000 pixels horizontally. Considering that annual gains in graphical processing performance are about $50 \%$, we estimate that the technological requirements for eye-resolution VR will not be met for the next 5-6 years (Table 4).

\footnotetext{
${ }^{21}$ https://clarkvision.com/imagedetail/eye-resolution.html; https:// wolfcrow.com/notes-by-dr-optoglass-the-resolution-of-the-human-eye/; https://www.theverge.com/ad/18113053/pixels-human-vision-8ktelevision.

${ }^{22}$ Human binocular vision captures about 200 degrees.
}

\section{Discussion and conclusions}

Over the last few years, we have witnessed a rapid proliferation of affordable off-the-shelf VR and AR devices that provide for increasingly immersive experiences of virtual environments that may not be achieved by other forms of techniques or technological interventions (Anthes et al., 2016; Heyselaar et al., 2017; Brookes et al., 2019). Having said that, even though the new generation of VR and AR devices has taken significant strides forward in terms of video and audio fidelity compared to older generations (Regan, 1995), technological advances over the next years in terms of graphical processing power and display technology are likely to bring about sophisticated VR/AR devices and content that will afford life-like virtual experiences. To what degree technological fidelity matters in the context of human perception, cognition, and emotion remains an open subject for academic research (Dinh et al., 1999; Nichols et al., 2000; Schuemie et al., 2001; Baños et al., 2000; Lin et al., 2002; Baños et al., 2004; Bowman \& Mcmahan, 2007; Riva et al., 2007; Alsina-Jurnet et al., 2007; Baumgartner, 2008; Slater et al., 2009; Gorini et al., 2010; Chessa et al., 2019; Chamilothori et al., 2019). Considering the complexity of the domain, there is no question that future research and knowledge discovery will continue to profit from multi- and interdisciplinary inquiries that adopt diverse perspectives to elucidate the human experience as it relates to virtual environments, in particular as it comes to mental well-being and psychological interventions (Turner \& Casey, 2014; Valmaggia et al., 2016).

There are a multitude of considerations for the strategic and effective use of VR technology in research. Producing video-based stimulus materials requires considerable effort 
Table 4 Projected increases in average computational graphics processing power

\begin{tabular}{|c|c|c|c|c|c|c|c|}
\hline Year & Hres (per eye) & Vres (per eye) & Pixels (per eye) & Total pixels & Annual increase & Resolution moniker & Year count \\
\hline 2016 & 1200 & 1080 & $1,296,000$ & $2,592,000$ & - & $1 \mathrm{~K}$ & 0 \\
\hline 2017 & 1470 & 1323 & $1,944,000$ & $3,888,000$ & $50 \%$ & $1.5 \mathrm{~K}$ & 1 \\
\hline 2018 & 1800 & 1620 & $2,916,000$ & $5,832,000$ & $50 \%$ & $2 \mathrm{~K}$ & 2 \\
\hline 2019 & 2205 & 1984 & $4,374,000$ & $8,748,000$ & $50 \%$ & $2 \mathrm{~K}$ & 3 \\
\hline 2020 & 2700 & 2430 & $6,561,000$ & $13,122,000$ & $50 \%$ & $2.5 \mathrm{~K}$ & 4 \\
\hline 2021 & 3307 & 2976 & $9,841,500$ & $19,683,000$ & $50 \%$ & $3 \mathrm{~K}$ & 5 \\
\hline 2022 & 4050 & 3645 & $14,762,250$ & $29,524,500$ & $50 \%$ & $4 \mathrm{~K}$ & 6 \\
\hline 2023 & 4960 & 4464 & $22,143,375$ & $44,286,750$ & $50 \%$ & $5 \mathrm{~K}$ & 7 \\
\hline 2024 & 6075 & 5468 & $33,215,063$ & $66,430,125$ & $50 \%$ & $6 \mathrm{~K}$ & 8 \\
\hline 2025 & 7440 & 6696 & $49,822,594$ & $99,645,188$ & $50 \%$ & $7.5 \mathrm{~K}$ & 9 \\
\hline 2026 & 9113 & 8201 & $74,733,891$ & $149,467,781$ & $50 \%$ & $9 \mathrm{~K}$ & 10 \\
\hline
\end{tabular}

Assuming an incremental annual improvement in the performance of graphics processing units of about $50 \%$ from one GPU generation to the next, one can estimate that it will take until the year 2025 until eye-resolution VR headsets and sufficiently powered graphics cards will be available as a mass market commodity. The major VR headsets that are currently available or announced (see Table 2) closely track the projected gains in resolution presented in this table

that needs to be taken into account when planning research activities, timelines, and budgets. This holds particularly true for 360-degree video in which post-processing of the source video files is more complicated compared to conventional video editing of rectangular video. This is due to the need for the managing, stitching, and processing of a number of source files to create a final spherical video that can be viewed through a VR headset. However, a major advantage of 360-degree video is that realistic, wellcontrolled stimulus materials can be readily captured with a suitable VR video camera. Put differently, 360-degree video is an accessible means for the creation of VR content that captures life-like social interactions. The challenging alternative to this approach would be to design, model, and animate computer-generated landscapes and populate these with digital agents that behave in a plausibly intelligent and/or convincingly realistic manner. The latter approach was out of the question for our research study on human-pet interactions. We recommend using the maximum resolution shared by both the VR video recording device and the postproduction video editing software to capture the source video. At or above a theoretical source resolution of $32 \mathrm{~K}$ (i.e., eye-resolution VR video), gains in visual fidelity should be imperceptible to the eye. During the piloting of the spherical 360-degree videos for our study, stereoscopic videos and frame refresh rates above 30 led to heightened rates of motion sickness. In addition, none of the video rendering software that we tested with the Oculus Rift reliably supported the playback of spherical videos above $4 \mathrm{~K}$. Our recommended settings for the creation of 360degree video are summarized in Table 5.

In terms of the selection of a VR headset, most devices currently available to end consumers offer comparable specifications in terms of resolution, refresh rate, and field of view, and it is unlikely that iterative advances over the next few years in any one of these parameters will result in significant leaps in realism and immersiveness of the VR content. Thus, a researcher's choice in regard to the purchase of any particular VR headset might be best determined by cost and personal preference. For optimal coverage and performance of positional tracking functionality, VR headsets that rely on external tracking sensors (i.e., outside-in tracking) are generally preferable in that they are able to sense movement of the user and that of peripheral equipment (e.g., hand controllers) that are not in the immediate coverage of the headset alone (e.g., rapid turns of the head; placing hands on the back). Similarly, if the presence of a cable connected to the VR headset is not a major concern, VR headsets that are tethered to a computer equipped with a high-performance GPU provide the highest visual fidelity and largest potential for simple near-future upgrades of the GPU (and the incremental gains in visual fidelity resulting from the upgrade) over having to replace the VR headset to achieve comparable gains.

Table 5 Recommended settings for the creation of 360-degree video for VR

\begin{tabular}{llll}
\hline Source resolution & Output resolution & Output FPS & Output video type \\
\hline Max. $(<=32 \mathrm{~K})$ & $<=4 \mathrm{~K}$ & 30 & Monoscopic \\
\hline
\end{tabular}


In this paper, we compiled our experiences and the lessons that we learned during a sizable experimental study on human emotion, VR technology, and companion animals. Our project exemplifies one of many potential innovative engagements of VR technology in academic research. The main objective of this paper is to support researchers in the planning and conduction of experimental research on immersive technology, virtual-reality experiences, and human-computer interactions. To that account, we presented our experiences pertaining to the institutional challenges that presented themselves to us regarding the use of live animals in our research study as well as those that emerged during our data collection with human participants. Furthermore, we presented practical knowledge on the use of VR technology and content, in general, and contemporary, off-the-shelf VR headsets and 360-degree video, in particular. Specifically, we discussed the methodological and technological challenges pertaining to the creation of 360-degree video and the use of virtual-reality technology in research.

Our main objective for this paper was to convey insights that help mitigate potential barriers to employing VR devices and content in experimental research and propagate their use in academic practice. As with any technology, piloting of the functioning of VR setups, devices, and content is strongly warranted to make sure that the chosen configurations are compatible and working properly and that the VR viewing experience is comfortable. Furthermore, the involvement of live animals in research will likely necessitate a full-committee IACUC review, which affords considerable allocation of effort and time. Based on the experiences that we discussed and the details that we provided, other researchers should be able to anticipate and strategically plan for these activities and successfully execute them in an efficient and deterministic manner.

Acknowledgements The research reported in this publication was partially supported by the National Institute of General Medical Sciences of the National Institutes of Health Award Number UL1GM118964. The content is solely the responsibility of the authors and does not necessarily represent the official views of the National Institutes of Health. The authors thank the following individuals who contributed technological assistance and/or aided in the experimental data collection for the study: Ridge Bynum, Xaaran Dolence, Jeanette Doorenbos, Nick Glover, Erin Grieschen, James Knight, Anastasiya Kozlovska, Alyssa Libak, Mary Macpherson, Hasan Mahmood, Rebecca Mudannayke, Vy-An Nguyen, Michael Nunnerley, Kira Rhodenhamel, Pista Szabo, and Amy Young.

\section{Compliance with Ethical Standards}

Conflict of interests The authors declare that they have no conflicts of interest.
Open Practice Statement The data and materials discussed in this manuscript are available from the corresponding author; none of the presented experiments were preregistered.

\section{References}

Abate, S. V., Zucconi, M., \& Boxer, B. A. (2011). Impact of canineassisted ambulation on hospitalized chronic heart failure patients' ambulation outcomes and satisfaction: A pilot study. The Journal of Cardiovascular Nursing, 26(3), 224-230.

Afzal, S., Chen, J., \& Ramakrishnan, K. K. (2017). Characterization of 360-degree videos. In Proceedings of the Workshop on Virtual Reality and Augmented Reality Network, VR/AR Network '17 (pp. 1-6), Los Angeles, CA, USA. Association for Computing Machinery.

Aitamurto, T., Zhou, S., Sakshuwong, S., Saldivar, J., Sadeghi, Y., \& Tran, A. (2018). Sense of presence, attitude change, perspectivetaking and usability in first-person split-sphere $360^{\circ}$ video. In Proceedings of the 2018 CHI Conference on Human Factors in Computing Systems, CHI '18 (pp. 1-12), Montreal QC, Canada. Association for Computing Machinery.

Allen, B., Hanley, T., Rokers, B., \& Green, C. S. (2016). Visual 3D motion acuity predicts discomfort in 3D stereoscopic environments. Entertainment Computing, 13, 1-9.

Alsina-Jurnet, I., Carvallo-Beciu, C., \& Gutiérrez-Maldonado, J. (2007). Validity of virtual reality as a method of exposure in the treatment of test anxiety. Behavior Research Methods, 39(4), 844-851.

Annerstedt, M., Jönsson, P., Wallergård, M., Johansson, G., Karlson, B., Grahn, P., ..., Währborg, P. (2013). Inducing physiological stress recovery with sounds of nature in a virtual reality forestresults from a pilot study. Physiology \& Behavior, 118, 240-250.

Anthes, C., García-hernández, R. J., Wiedemann, M., \& Kranzlmüller, D. (2016). State of the art of virtual reality technology. In 2016 IEEE, Aerospace Conference (pp. 1-19).

Banks, M. R., Willoughby, L. M., \& Banks, W. A. (2008). Animalassisted therapy and loneliness in nursing homes: Use of robotic versus living dogs. Journal of the American Medical Directors Association, 9(3), 173-177.

Baños, R., Botella, C., Garcia-palacios, A., Villa, H., Perpiña, C., \& Alcañiz, M. (2000). Presence and reality judgment in virtual environments: A unitary construct?. CyberPsychology \& Behavior, 3(3), 327-335.

Baños, R., Botella, C., Alcañiz, M., Liaño, V., Guerrero, B., \& Rey, B. (2004). Immersion and emotion: Their impact on the sense of presence. CyberPsychology \& Behavior, 7(6), 734-741.

Baños, R. M., Botella, C., Rubió, I., Quero, S., García-palacios, A., \& Alcañiz, M. (2008). Presence and emotions in virtual environments: The influence of stereoscopy. CyberPsychology \& Behavior, 11(1), 1-8.

Baumans, V. (2004). Use of animals in experimental research: An ethical dilemma? Gene Therapy, $11 \operatorname{Suppl(1),~S64-66.~}$

Baumgartner, T. (2008). Feeling present in arousing virtual reality worlds: Prefrontal brain regions differentially orchestrate presence experience in adults and children. Frontiers in Human Neuroscience, 2.

Baun, M. M., Bergstrom, N., Langston, N. F., \& Thoma, L. (1984). Physiological effects of human/companion animal bonding. Nursing Research, 33(3), 126-129.

Benzina, N., Morgiève, M., Euvrard, M., Flores alves dos santos, J., Pelissolo, A., \& Mallet, L. (2020). Personalised $360^{\circ}$, video exposure therapy for the treatment of obsessive-compulsive 
disorder: A single case study. French Journal of Psychiatry, 1, 31-38.

Berget, B., \& Grepperud, S. (2011). Animal-assisted interventions for psychiatric patients: Beliefs in treatment effects among practitioners. European Journal of Integrative Medicine, 3(2), e91-e96.

Bessa, M., Melo, M., Narciso, D., Barbosa, L., \& VasconcelosRaposo, J. (2016). Does 3D 360 video enhance user's VR experience? an evaluation study. In Proceedings of the XVII International Conference on Human Computer Interaction (pp. 1-4), Salamanca, Spain. Association for Computing Machinery.

Bohil, C. J., Alicea, B., \& Biocca, F. A. (2011). Virtual reality in neuroscience research and therapy. Nature Reviews Neuroscience, 12(12), 752-762.

Boletsis, C. (2017). The new era of virtual reality locomotion: A systematic literature review of techniques and a proposed typology. Multimodal Technologies and Interaction, 1(4), 24.

Bonetti, F., Warnaby, G., \& Quinn, L. (2018). Augmented reality and virtual reality in physical and online retailing: A review, synthesis and research agenda. In Jung, T., \& tom Dieck, M. C. (Eds.) Augmented Reality and Virtual Reality: Empowering Human, Place and Business, Progress in IS, (pp. 119-132). Cham: Springer International Publishing.

Bowman, D., \& Mcmahan, R. (2007). Virtual reality: How much immersion is enough? Computer, 40(7), 36-43.

Brookes, J., Warburton, M., Alghadier, M., Mon-Williams, M., \& Mushtaq, F. (2019). Studying human behavior with virtual reality: The unity experiment framework. Behavior Research Methods.

Caporale, V., Alessandrini, B., Villa, P. D., \& Del Papa, S. (2005). Global perspectives on animal welfare: Europe. Revue Scientifique et Technique-Office, International des Epizooties, 24(2), 567.

Chamilothori, K., Wienold, J., \& Andersen, M. (2019). Adequacy of immersive virtual reality for the perception of daylit spaces: Comparison of real and virtual environments. LEUKOS, 15(2-3), 203-226.

Charry-Sánchez, J. D., Pradilla, I., \& Talero-Gutiérrez, C. (2018). Animal-assisted therapy in adults: A systematic review. Complementary Therapies in Clinical Practice, 32, 169-180.

Chessa, M., Maiello, G., Borsari, A., \& Bex, P. J. (2019). The perceptual quality of the oculus rift for immersive virtual reality. Human-Computer Interaction, 34(1), 51-82.

Corbillon, X., Simon, G., Devlic, A., \& Chakareski, J. (2017). Viewport-adaptive navigable 360-degree video delivery. In 2017 IEEE, International Conference on Communications (ICC) (pp. 1-7).

Damiani, L., Demartini, M., Guizzi, G., Revetria, R., \& Tonelli, F. (2018). Augmented and virtual reality applications in industrial systems: A qualitative review towards the industry 4.0 era. IFACPapersOnLine, 51(11), 624-630.

Diemer, J., Mühlberger, A., Pauli, P., \& Zwanzger, P. (2014). Virtual reality exposure in anxiety disorders: Impact on psychophysiological reactivity. The World Journal of Biological Psychiatry, 15(6), 427-442.

Dinh, H., Walker, N., Hodges, L., Song, C., \& Kobayashi, A. (1999). Evaluating the importance of multi-sensory input on memory and the sense of presence in virtual environments. In IEEE Virtual Reality, 1999, Proceedings (pp. 222-228).

Domański, M., Stankiewicz, O., Wegner, K., \& Grajek, T. (2017). Immersive visual media - MPEG-i: 360 video, virtual navigation and beyond. In 2017 International Conference on Systems, Signals and Image Processing (IWSSIP) (pp. 1-9).

Duffy, D. L., Kruger, K. A., \& Serpell, J. A. (2014). Evaluation of a behavioral assessment tool for dogs relinquished to shelters. Preventive Veterinary Medicine, 117(3), 601-609.
Ekkekakis, P., \& Russell, J. A. (2013). The measurement of affect, mood and emotion: A guide for health-behavioral research. Cambridge: Cambridge University Press.

Everitt, J. I., \& Berridge, B. R. (2017). The role of the IACUC, in the design and conduct of animal experiments that contribute to translational success. ILAR Journal, 58(1), 129-134.

Faria, J. W. V. d., Teixeira, M. J., Júnior, L. d. M. S., Otoch, J. P., \& Figueiredo, E. G. (2016). Virtual and stereoscopic anatomy: When virtual reality meets medical education. Journal of Neurosurgery, 125(5), 1105-1111.

Felnhofer, A., Kothgassner, O. D., Schmidt, M., Heinzle, A., Beutl, L., \& Hlavacs, H. (2015). Kryspin-Exner, I Is virtual reality emotionally arousing? investigating five emotion inducing virtual park scenarios. International Journal of Human-Computer Studies, 82, 48-56.

Ferdig, R. E., \& Kosko, K. W. (2020). Implementing 360 video to increase immersion, perceptual capacity, and teacher noticing. TechTrends.

Feuerbacher, E. N., \& Wynne, C. D. L. (2015). Shut up and pet me! domestic dogs (Canis lupus familiaris) prefer petting to vocal praise in concurrent and single-alternative choice procedures. Behavioural Processes, 110, 47-59.

Frans Fela, R., Zacharov, N., \& Forchhammer, S. (2020). Towards a perceived audiovisual quality model for immersive content. arXiv e-prints, 2005: arXiv:2005.09309.

Friedmann, E., \& Thomas, S. A. (1995). Pet ownership, social support, and one-year survival after acute myocardial infarction in the cardiac arrhythmia suppression trial (CAST). The American Journal of Cardiology, 76(17), 1213-1217.

Giuliani, F., \& Jacquemettaz, M. (2017). Animal-assisted therapy used for anxiety disorders in patients with learning disabilities: An observational study. European Journal of Integrative Medicine, 14, 13-19.

Gorini, A., Capideville, C. S., De Leo, G., Mantovani, F., \& Riva, G. (2010). The role of immersion and narrative in mediated presence: The virtual hospital experience. Cyberpsychology, Behavior, and Social Networking, 14(3), 99-105.

Halarnkar, P. N., Shah, S., Shah, H. D., Shah, H. A., \& Shah, A. (2012). A review on virtual reality. Journal of Computer Science Issues, 9,6 .

Henn, J. S., Lemole, G. M., Ferreira, M. A. T., Gonzalez, L. F., Schornak, M., Preul, M. C., \& Spetzler, R. F. (2002). Interactive stereoscopic virtual reality: A new tool for neurosurgical education. Journal of Neurosurgery, 96(1), 144-149.

Heyselaar, E., Hagoort, P., \& Segaert, K. (2017). In dialogue with an avatar, language behavior is identical to dialogue with a human partner. Behavior Research Methods, 49(1), 46-60.

Hosey, G., \& Melfi, V. (2014). Human-animal interactions, relationships and bonds: A review and analysis of the literature. International Journal of Comparative Psychology, 27(1), 117-142.

Hosseini, M., \& Swaminathan, V. (2016). Adaptive 360 VR video streaming: Divide and conquer. In 2016 IEEE, International Symposium on Multimedia (ISM) (pp. 107-110).

Howard, M. C. (2017). A meta-analysis and systematic literature review of virtual reality rehabilitation programs. Computers in Human Behavior, 70, 317-327.

Hsu, Y., \& Serpell, J. A. (2003). Development and validation of a questionnaire for measuring behavior and temperament traits in pet dogs. Journal of the American Veterinary Medical Association, 223(9), 1293-1300.

Hu, M., Zhang, P., Leng, M., Li, C., \& Chen, L. (2018). Animalassisted intervention for individuals with cognitive impairment: A meta-analysis of randomized controlled trials and quasirandomized controlled trials. Psychiatry Research, 260, 418-427. 
Hu, Y., Elwardy, M., \& Zepernick, H. (2020). On the effect of standing and seated viewing of $360^{\circ}$ videos on subjective quality assessment. In 2020 IEEE, Conference on Virtual Reality and 3D User Interfaces Abstracts and Workshops (VRW) (pp. 285-286).

Hwa Choi, D. (2016). Emerging tools and applications of virtual reality in education. IGI Global.

IJsselsteijn, W., Ridder, H. d., Freeman, J., Avons, S. E., \& Bouwhuis, D. (2001). Effects of stereoscopic presentation, image motion, and screen size on subjective and objective corroborative measures of presence. Presence: Teleoperators and Virtual Environments, 10(3), 298-311.

Ilgner, J. F. R., Kawai, T., Shibata, T., Yamazoe, T., \& Westhofen, M. (2006). Evaluation of stereoscopic medical video content on an autostereoscopic display for undergraduate medical education. In Stereoscopic Displays and Virtual Reality Systems XIII (vol. 6055, pp. 605506). International Society for Optics and Photonics.

Institute of Medicine (US) and National Research Council (US) (2012). International animal research regulations: Impact on neuroscience research: Workshop summary The National Academies Collection: Reports funded by National Institutes of Health, National Academies Press (US), Washington (DC).

Jung, T., \& tom Dieck, M. C. (2017). Augmented reality and virtual reality: Empowering human, place and business. Springer Publishing Company, Incorporated, 1st edition.

Kaminski, J., Waller, B. M., Diogo, R., Hartstone-rose, A., \& Burrows, A. M. (2019). Evolution of facial muscle anatomy in dogs. Proceedings of the National Academy of Sciences, 116(29), 14677-14681.

Kamioka, H., Okada, S., Tsutani, K., Park, H., Okuizumi, H., Handa, S., ..., Mutoh, Y. (2014). Effectiveness of animal-assisted therapy: A systematic review of randomized controlled trials. Complementary Therapies in Medicine, 22(2), 371-390.

Kavanagh, S., Luxton-Reilly, A., Wüensche, B., \& Plimmer, B. (2016). Creating $360^{\circ}$ educational video: A case study. In Proceedings of the 28th Australian Conference on ComputerHuman Interaction, OzCHI '16, page 34-39, Launceston, Tasmania, Australia. Association for Computing Machinery.

Kavanagh, S., Luxton-reilly, A., Wuensche, B., \& Plimmer, B. (2017). A systematic review of virtual reality in education. Themes in Science and Technology Education, 10(2), 85-119.

Kekecs, Z., Szollosi, A., Palfi, B., Szaszi, B., Kovacs, K. J., Dienes, Z., \& Aczel, B. (2016). Commentary: Oxytocin-gaze positive loop and the coevolution of human-dog bonds. Frontiers in Neuroscience, 10.

Keshavarz, B., \& Hecht, H. (2012). Stereoscopic viewing enhances visually induced motion sickness but sound does not. Presence: Teleoperators and Virtual Environments, 21(2), 213-228.

Kopf, J. (2016). $360^{\circ}$ video stabilization. ACM Transactions on Graphics, 35(6), 195:1-195:9.

Kruger, K. A., \& Serpell, J. A. (2010). Animal-assisted interventions in mental health. In Handbook on Animal-Assisted Therapy, (33-48). Elsevier.

Kuhne, F., Hößler, J. C., \& Struwe, R. (2012a). Effects of humandog familiarity on dogs' behavioural responses to petting. Applied Animal Behaviour Science, 142(3), 176-181.

Kuhne, F., Hössler, J. C., \& Struwe, R. (2012b). Affective behavioural responses by dogs to tactile human-dog interactions. Berliner und Munchener Tierarztliche Wochenschrift, 125(9-10), 371-378.

Lambooij, M. T. M., IJsselsteijn, W. A., \& Heynderickx, I. (2007). Visual discomfort in stereoscopic displays: A review. In Stereoscopic Displays and Virtual Reality Systems XIV (vol. 6490, pp. 64900I). International Society for Optics and Photonics.

Lee, G. A., Teo, T., Kim, S., \& Billinghurst, M. (2018). A user study on MR remote collaboration using live 360 video. In 2018 IEEE, International Symposium on Mixed and Augmented Reality (ISMAR) (pp. 153-164).
Levine, G. N., Allen, K., Braun, L. T., Christian, H. E., Friedmann, E., Taubert, K. A., ..., Nursing, S. (2013). Pet ownership and cardiovascular risk: A scientific statement from the American Heart Association. Circulation, 127(23), 2353-2363.

Lin, J., Duh, H., Parker, D., Abi-rached, H., \& Furness, T. (2002). Effects of field of view on presence, enjoyment, memory, and simulator sickness in a virtual environment. In IEEE Virtual Reality, 2002 Proceedings (pp. 164-171).

Lindsay, S. R. (2000). Handbook of applied dog behavior and training: Adaptation and learning (Vol. 1). Iowa State University Press.

Ling, Y., Brinkman, W., Nefs, H. T., Qu, C., \& Heynderickx, I. (2012). Effects of stereoscopic viewing on presence, anxiety, and cybersickness in a virtual reality environment for public speaking. Presence: Teleoperators and Virtual Environments, 21(3), 254267.

Lord, L. K., Reider, L., Herron, M. E., \& Graszak, K. (2008). Health and behavior problems in dogs and cats one week and one month after adoption from animal shelters. Journal of the American Veterinary Medical Association, 233(11), 1715-1722.

Loup-Escande, E., Jamet, E., Ragot, M., Erhel, S., \& Michinov, N. (2017). Effects of stereoscopic display on learning and user experience in an educational virtual environment. International Journal of Human-Computer, Interaction, 33(2), 115-122.

Maber-Aleksandrowicz, S., Avent, C., \& Hassiotis, A. (2016). A systematic review of animal-assisted therapy on psychosocial outcomes in people with intellectual disability. Research in Developmental Disabilities, 49-50, 322-338.

Mabrook, R., \& Singer, J. B. (2019). Virtual reality, $360^{\circ}$ video, and journalism studies: Conceptual approaches to immersive technologies. Journalism Studies, 20(14), 2096-2112.

Malloy, K. M., \& Milling, L. S. (2010). The effectiveness of virtual reality distraction for pain reduction: A systematic review. Clinical Psychology Review, 30(8), 1011-1018.

Marshall-Pescini, S., Rao, A., Virányi, Z., \& Range, F. (2017). The role of domestication and experience in 'looking back' towards humans in an unsolvable task. Scientific Reports, 7(1), 46636.

Mazumder, R., Spiers, H., \& Ellard, C. (2020). Exposure to high-rise buildings negatively influences affect: Evidence from real-world and 360-degree video. preprint, PsyArXiv.

McCune, S., Kruger, K. A., Griffin, J. A., Esposito, L., Freund, L. S., Hurley, K. J., \& Bures, R. (2014). Evolution of research into the mutual benefits of human-animal interaction. Animal Frontiers, 4(3), 49-58.

Meyer, I., \& Forkman, B. (2014). Nonverbal communication and human-dog interaction. Anthrozoös, 27(4), 553-568.

Meyerbröker, K., \& Emmelkamp, P. M. (2010). Virtual reality exposure therapy in anxiety disorders: A systematic review of process-and-outcome studies. Depression and Anxiety, 27(10), 933-944.

Miller, S. C., Kennedy, C. C., Devoe, D. C., Hickey, M., Nelson, T., \& Kogan, L. (2009). An examination of changes in oxytocin levels in men and women before and after interaction with a bonded dog. Anthrozoös, 22(1), 31-42.

Monamy, V. (2017). Animal experimentation: A guide to the issues. Cambridge University Press, Cambridge, United Kingdom, 3 edition.

Moyle, W., Cooke, M., Beattie, E., Jones, C., Klein, B., Cook, G., \& Gray, C. (2013). Exploring the effect of companion robots on emotional expression in older adults with dementia: A pilot randomized controlled trial. Journal of Gerontological Nursing, 39(5), 46-53.

Munafo, J., Diedrick, M., \& Stoffregen, T. A. (2017). The virtual reality head-mounted display Oculus Rift induces motion sickness and is sexist in its effects. Experimental Brain Research, 235(3), 889-901. 
Nagasawa, M., Mitsui, S., En, S., Ohtani, N., Ohta, M., Sakuma, Y., ..., Kikusui, T. (2015). Oxytocin-gaze positive loop and the coevolution of human-dog bonds. Science, 348(6232), 333-336.

Nasrabadi, A. T., Mahzari, A., Beshay, J. D., \& Prakash, R. (2017). Adaptive 360-degree video streaming using layered video coding. In 2017 IEEE, Virtual Reality (VR) (pp. 347-348).

Nee, A. Y. C., \& Ong, S. K. (2013). Virtual and augmented reality applications in manufacturing. IFAC Proceedings Volumes, 46(9), $15-26$.

Neumann, D. L., Moffitt, R. L., Thomas, P. R., Loveday, K., Watling, D. P., Lombard, C. L., ..., Tremeer, M. A. (2018). A systematic review of the application of interactive virtual reality to sport. Virtual Reality, 22(3), 183-198.

Nichols, S., Haldane, C., \& Wilson, J. R. (2000). Measurement of presence and its consequences in virtual environments. International Journal of Human-Computer, Studies, 52(3), 471-491.

Palma, C. D., Viggiano, E., Barillari, E., Palme, R., Dufour, A. B., Fantini, C., \& Natoli, E. (2005). Evaluating the temperament in shelter dogs. Behaviour, 142(9/10), 1307-1328.

Pan, X., \& Hamilton, A. F. d. C. (2018). Why and how to use virtual reality to study human social interaction: The challenges of exploring a new research landscape. British Journal of Psychology, 395-417.

Qian, F., Ji, L., Han, B., \& Gopalakrishnan, V. (2016). Optimizing 360 video delivery over cellular networks. In Proceedings of the 5th Workshop on All Things Cellular: Operations, Applications and Challenges, ATC '16 (pp. 1-6). New York City, New York. Association for Computing Machinery.

Qian, F., Han, B., Xiao, Q., \& Gopalakrishnan, V. (2018). Flare: practical viewport-adaptive 360-degree video streaming for mobile devices. In Proceedings of the 24th Annual International Conference on Mobile Computing and Networking, MobiCom '18 (pp. 99-114). New Delhi, India. Association for Computing Machinery.

Regan, E. C. (1995). Some evidence of adaptation to immersion in virtual reality. Displays, 16(3), 135-139.

Riva, G., Mantovani, F., Capideville, C. S., Preziosa, A., Morganti, F., Villani, D., ..., Alcañiz, M. (2007). Affective interactions using virtual reality: The link between presence and emotions. CyberPsychology \& Behavior, 10(1), 45-56.

Roche, L., \& Gal-Petitfaux, N. (2017). Using $360^{\circ}$ video in physical education teacher education (pp. 3420-3425). Association for the Advancement of Computing in Education (AACE).

Rubio-Tamayo, J. L., Gertrudix Barrio, M., \& García García, F. (2017). Immersive environments and virtual reality: Systematic review and advances in communication, interaction and simulation. Multimodal Technologies and Interaction, 1(4), 21.

Rupp, M. A., Kozachuk, J., Michaelis, J. R., Odette, K. L., Smither, J. A., \& Mcconnell, D. S. (2016). The effects of immersiveness and future VR expectations on subjective experiences during an educational $360^{\circ}$ video. Proceedings of the Human Factors and Ergonomics Society Annual Meeting, 60(1), 2108-2112.

Rupp, M. A., Odette, K. L., Kozachuk, J., Michaelis, J. R., Smither, J. A., \& Mcconnell, D. S. (2019). Investigating learning outcomes and subjective experiences in 360-degree videos. Computers \& Education, 128, 256-268.

Schild, J., LaViola, J., \& Masuch, M. (2012). Understanding user experience in stereoscopic 3D games. In Proceedings of the SIGCHI Conference on Human Factors in Computing Systems, CHI '12 (pp. 89-98), Austin, Texas, USA. Association for Computing Machinery.

Schöne, B., Sylvester, R. S., Radtke, E. L., \& Gruber, T. (2020). Sustained inattentional blindness in virtual reality and under conventional laboratory conditions. Virtual Reality.
Schuemie, M. J., van der Straaten, P., Krijn, M., \& van der Mast, C. A. (2001). Research on presence in virtual reality: A survey. CyberPsychology \& Behavior, 4(2), 183-201.

Schultze, U. (2010). Embodiment and presence in virtual worlds: A review. Journal of Information Technology, 25(4), 434-449.

Serpell, J. (1991). Beneficial effects of pet ownership on some aspects of human health and behaviour. Journal of the Royal Society of Medicine, 84(12), 717-720.

Serrano, B., Baños, R. M., \& Botella, C. (2016). Virtual reality and stimulation of touch and smell for inducing relaxation: A randomized controlled trial. Computers in Human Behavior, 55, Part A, 1-8.

Silverman, J., Suckow, M. A., \& Murthy, S. (Eds.) (2014). The IACUC Handbook, 3rd ed. Boca Raton: CRC Press.

Sinmez, C. C., \& Yasar, A. (2019). Experimental animal use in Turkey: A comparison with other countries. Alternatives to Laboratory Animals, 47(2), 82-92.

Slater, M., Lotto, B., Arnold, M. M., \& Sanchez-Vives, M. V. (2009). How we experience immersive virtual environments: The concept of presence and its measurement. Anuario de psicología / The UB Journal of Psychology, 40(2), 193-210.

Stanney, K. (1995). Realizing the full potential of virtual reality: Human factors issues that could stand in the way. In Proceedings Virtual Reality Annual International Symposium '95 (pp. 28-34).

Stefanini, M. C., Martino, A., Allori, P., Galeotti, F., \& Tani, F. (2015). The use of animal-assisted therapy in adolescents with acute mental disorders: A randomized controlled study. Complementary Therapies in Clinical Practice, 21(1), 42-46.

Stupar-Rutenfrans, S., Ketelaars, L. E. H., \& van Gisbergen, M. S. (2017). Beat the fear of public speaking: Mobile $360^{\circ}$ video virtual reality exposure training in home environment reduces public speaking anxiety. Cyberpsychology, Behavior, and Social Networking, 20(10), 624-633.

$\mathrm{Su}$, Y., \& Grauman, K. (2017). Making $360^{\circ}$ video watchable in 2D: learning videography for click free viewing. In 2017 IEEE, Conference on Computer Vision and Pattern Recognition (CVPR) (pp. 1368-1376).

Tan, J., Cheung, G., \& Ma, R. (2018). 360-degree virtual-reality cameras for the masses. IEEE MultiMedia, 25(1), 87-94.

Téglás, E., Gergely, A., Kupán, K., Miklósi, D., \& Topál, J. (2012). Dogs' gaze following is tuned to human communicative signals. Current Biology, 22(3), 209-212.

Tran, H. T. T., Ngoc, N. P., Bui, C. M., Pham, M. H., \& Thang, T. C. (2017). An evaluation of quality metrics for 360 videos. In 2017 Ninth International Conference on Ubiquitous and Future Networks (ICUFN) (pp. 7-11).

Tran, H. T. T., Pham, C. T., Ngoc, N. P., Pham, A. T., \& Thang, T. C. (2018). A study on quality metrics for 360 video communications. IEICE TRANSACTIONS on Information and Systems, E101-D(1), $28-36$.

Tse, A., Jennett, C., Moore, J., Watson, Z., Rigby, J., \& Cox, A. L. (2017). Was I there? Impact of platform and headphones on 360 video immersion. In Proceedings of the 2017 CHI Conference Extended Abstracts on Human Factors in Computing Systems, CHI EA '17 (pp. 2967-2974), Denver, Colorado, USA. Association for Computing Machinery.

Turner, W. A., \& Casey, L. M. (2014). Outcomes associated with virtual reality in psychological interventions: Where are we now? Clinical Psychology Review, 34(8), 634-644.

Valmaggia, L. R., Latif, L., Kempton, M. J., \& Rus-calafell, M. (2016). Virtual reality in the psychological treatment for mental health problems: An systematic review of recent evidence. Psychiatry Research, 236, 189-195.

Van den Broeck, M., Kawsar, F., \& Schöning, J. (2017). It's all around you: Exploring $360^{\circ}$ video viewing experiences on 
mobile devices. In Proceedings of the 25th ACM international conference on Multimedia, MM '17 (pp. 762-768), Mountain View, California, USA. Association for Computing Machinery.

Van Damme, K., All, A., De Marez, L., \& Van Leuven, S. (2019). 360 video journalism: Experimental study on the effect of immersion on news experience and distant suffering. Journalism Studies, 20(14), 2053-2076.

Vrbanac, Z., Zecević, I., Ljubić, M., Belić, M., Stanin, D., Bottegaro, N. B., .., Zubcić, D. (2013). Animal-assisted therapy and perception of loneliness in geriatric nursing home residents. Collegium Antropologicum, 37(3), 973-976.

Waller, B. M., Peirce, K., Caeiro, C. C., Scheider, L., Burrows, A. M., McCune, S., \& Kaminski, J. (2013). Paedomorphic facial expressions give dogs a selective advantage. PLOS ONE, 8(12).

Wiener, P., \& Haskell, M. J. (2016). Use of questionnaire-based data to assess dog personality. Journal of Veterinary Behavior, 16, 81-85.

Wilson, C. C. (1991). The pet as an anxiolytic intervention. The Journal of Nervous and Mental Disease, 179(8), 482-489.

Wright, J. C., \& Nesselrote, M. S. (1987). Classification of behavior problems in dogs: Distributions of age, breed, sex and reproductive status. Applied Animal Behaviour Science, 19(1), 169-178.
Xie, L., Xu, Z., Ban, Y., Zhang, X., \& Guo, Z. (2017). 360ProbDASH: improving QoE of 360 video streaming using tile-based HTTP adaptive streaming. In Proceedings of the 25th ACM international conference on Multimedia, MM '17 (PP. 315-323), Mountain View, California, USA. Association for Computing Machinery.

Xu, M., Li, C., Zhang, S., \& Callet, P. L. (2020). State-of-theart in $360^{\circ}$, video/image processing: Perception, assessment and compression. IEEE Journal of Selected Topics in Signal Processing, 14(1), 5-26.

Yung, R., \& Khoo-lattimore, C. (2019). New realities: A systematic literature review on virtual reality and augmented reality in tourism research. Current Issues in Tourism, 22(17), 2056-2081.

Zheng, J., Chan, K., \& Gibson, I. (1998). Virtual reality. IEEE Potentials, 17(2), 20-23.

Zolfaghari, M., Austin, C. K., Kosko, K. W., \& Ferdig, R. E. (2020). Creating asynchronous virtual field experiences with $360^{\circ}$ video. Journal of Technology and Teacher Education, 28(2), 315-320.

Publisher's note Springer Nature remains neutral with regard to jurisdictional claims in published maps and institutional affiliations. 